\title{
Investigações Brasileiras em Busca de Tecidos Moles Preservados em Fósseis
}

\author{
Everton Fernando Alves \\ 凹efalves.mga@gmail.com
}

1. PaleoMol - Laboratório Virtual de Paleontologia Molecular, Paraná - Brasil.

Histórico do Artigo:

Recebido em: 01 de fevereiro de $2021 \quad$ Aceito em: 15 de fevereiro de $2021 \quad$ Publicado em: 30 de abril de 2021

Resumo: Duas subáreas da Paleontologia que têm se destacado são a Tafonomia Experimental e, especialmente, a Tafonomia Molecular, que se baseia em diferentes técnicas para compreender não só os processos de fossilização de tecidos moles, mas também para identificar e caracterizar biomoléculas antigas originais. Esta perspectiva profissional traz definições de Paleontologia Molecular e tecidos moles, faz um apanhado histórico das principais investigações brasileiras nesse campo e traça uma perspectiva futura sobre as possíveis abordagens nessa área.

Palavras-chave: Paleontologia Molecular, Tafonomia Molecular, Tecidos moles não mineralizados, Biomoléculas originais.

\section{Brazilian Investigations in Search for Soft Tissues Preserved in Fossils}

Abstract: Two sub-areas of the Paleontology that have stood out are Experimental taphonomy and, especially, Molecular taphonomy, which is based on different techniques to understand not only the processes of fossilization of soft tissues, but also to identify and characterize original ancient biomolecules. This professional perspective brings definitions of Molecular paleontology and soft tissues, provides a historical overview of the main Brazilian investigations in this field and outlines a future perspective on possible approaches in this area.

Keywords: Molecular Paleontology, Molecular Taphonomy, Non-mineralized soft tissues, Original biomolecules.

\section{Investigaciones Brasileñas en Busca de Tejidos Blandos Preservados en Fósiles}

Resumen: Dos subáreas de la Paleontología que se han destacado son la Tafonomía Experimental y, especialmente, la Tafonomía Molecular, que se basa en diferentes técnicas para comprender no solo los procesos de fosilización de tejidos blandos, sino también para identificar y caracterizar biomoléculas antiguas originales. Esta perspectiva profesional aporta definiciones de la Paleontología Molecular y de tejidos blandos, ofrece un panorama histórico de las principales investigaciones brasileñas en este campo y esboza una perspectiva futura sobre posibles enfoques en esta área.

Palabras clave: Paleontología molecular, Tafonomía molecular, Tejidos blandos no mineralizado, Biomoléculas originales. 


\section{INTRODUÇ̃̃o}

0s tecidos moles presentes em fósseis são todas aquelas estruturas teciduais, celulares e/ou moleculares, que não são tecidos originalmente mineralizados (e.g., ossos), e que podem ser encontradas, em relação à diagênese das rochas, sob as formas mineralizadas (totalmente substituídas por minerais), parcialmente mineralizadas, ou ainda não mineralizadas; neste último caso, as estruturas não foram substituídas por minerais durante a fossildiagênese (SCHWEITZER, 2003; SCHWEITZER, 2004; ALVES; MACHAD0, 2020).

A Paleontologia Molecular é o campo de pesquisa interdisciplinar responsável pela recuperação e caracterização dos achados de tecidos moles originais identificáveis nos fósseis de seres extintos das mais diversas idades geológicas com o auxílio de distintas técnicas moleculares avançadas de deteç̧ão ultraestruturais (SCHWEITZER, 2003; SCHWEITZER, 2004).

A Paleontologia Molecular tem crescido exponencialmentee as pesquisas estrangeiras têm produzido um grande volume de dados científicos por meio da exploração de fósseis em busca de biomoléculas orgânicas a fim de entender melhor a biologia e os processos evolutivos de organismos extintos. 0 Brasil também possui um grande potencial na exploração de tecidos moles não mineralizados em fósseis, especialmente de vertebrados mesozóicos, uma vez que possui um dos maiores Konservät-Lagerstätten do mundo, inclusive com material fossilífero característico de preservação tridimensional (KELLNER, 2015; KELLNER; SOARES, 2019).

No Brasil, os estudos iniciais com tecidos moles mineralizados se deram a partir de 1999, época em que foi possível utilizar a técnica de microscopia eletrônica de varredura em alguns exemplares de vertebrados fósseis. A descoberta mais famosa foi a de vasos sanguíneos e fibras musculares preservados no fóssil do dinossauro terópode Santanaraptor placidus Kellner, 1999 encontrado no interior do Ceará, na Bacia do Araripe (KELLNER, 1999).

Aliás, uma técnica que vem ganhando reconhecimento nos estudos de tecidos moles mineralizados no Brasil é a paleometria, uma abordagem integrada entre Física e Paleontologia, que objetiva identificar e caracterizar os compostos químicos ainda presentes nos organismos fossilizados (BECKERet al., 2014). A importância dessa técnica para o estudo de fósseis raros se dá exatamente por se configurar como pouco destrutiva para o estudo do registro fossilífero. Existem diferentes tipos de técnicas paleométricas, tais como a de infravermelho, espectroscopia Raman, difração de raios X e fluorescência de raios-X.

Os principais trabalhos de paleometria no Brasil vêm de estudos na Bacia do Araripe (SAYÃ0; BANTIM, 2015). Em 2006, se iniciou um estudo pioneiro conduzido por Ricardo Lima e 
colaboradores, que analisou, por meio de difração de raios-X e espectroscopia na região do infravermelho, amostras retiradas de escamas fósseis de um peixe da espécie Rhacolepis buccalis Agassiz, 1841 encontrado em uma concreção calcária da Formação Romualdo (LIMA et al., 2007). Os resultados indicaram que a maior parte da composição química da amostra se assemelhava à de escamas de peixes atuais, significando que a fossilização pouco alterou a composição das escamas.

Pesquisas na área de Paleobotânica também têm sido conduzidas no Brasil. Desde 2006, por exemplo, o paleogeoquímico e paleobotânico Ricardo Pereira, do Departamento de Geologia da Universidade Federal de Pernambuco, e o paleontólogo Ismar de Souza Carvalho, do Instituto de Geociências da Universidade Federal do Rio de Janeiro, e colaboradores, têm conduzido pesquisas de caracterização geoquímica e molecular de folhelho, âmbares e vegetais fossilizados de Bacias Sedimentares do Nordeste do Brasil, utilizando técnicas analíticas diversas, tais como cromatografia gasosa convencional e bidimensional acopladas à espectrometria de massas quadrupolar, e espectrometria de massas de razão isotópica (PEREIRA et al., 2006; 2009a; 2009b; 201la; 201lb; 2020). 0s grupos de compostos orgânicos encontrados nas amostras têm possibilitado identificar taxonomicamente distintos grupos de plantas.

É válido mencionar que nesta breve perspectiva não estou considerando nem mesmo aqueles fósseis de diversos táxons brasileiros traficados para fora do país, que poderiam render inúmeras pesquisas brasileiras, nos quais os pesquisadores estrangeiros que os estudaram descobriram múltiplos achados de tecidos moles do tipo mineralizados e não mineralizados (MARTILL, 1989; MARTILL; UNWIN, 1989; FREY; TISCHLINGER, 2000; FREY et al., 2003; VINTHER et al., 2008; SMYTH et al., 2020).

Em 2016, outro grupo de pesquisa coordenado pela tafônoma Mirian Forancelli Pacheco, do Departamento de Biologia da Universidade Federal de São Carlos (Campus Sorocaba), coordenou uma investigação paleométrica utilizando diversas técnicas complementares a fim de entender a preservação de tecidos moles mineralizados e lábeis em insetos fósseis. Os resultados da pesquisa sugeriram que biofilmes bacterianos auxiliaram em sua decomposição e preservação (OSÉSet al., 2016). 0 mesmo grupo de pesquisa ainda descobriu, dentre outros, diversos tipos de tecidos moles piritizados ou querogenizados de peixes da Formação Santana (OSÉSet al., 2017), e de penas penáceas carbonizadas de aves aquáticas e penas mineralizadas do tipo plumuláceas, felpudas e de contorno, de dinossauros celurossauros das Formações Tremembé e Santana, sucessivamente (PRAD0 et al., 2016a; 2016b). 
Além disso, o campo praticamente inexplorado de investigação de tecidos moles não mineralizados abre inúmeras outras oportunidades de abordagens para pesquisas brasileiras (KELLNER; SOARES, 2019). Em 2009, por exemplo, um estudo liderado pelo pterossaurólogo Alexander Kellner, diretor do Museu Nacional da Universidade Federal do Rio de Janeiro, analisou um fóssil de um pterossauro chinês, Jeholopterus ningchengensis, e encontrou tecidos moles originais do tipo Picnofibras ("pelos") e bainha queratinosa em ungueal de mão direita (KELLNER et al., 2009).

Em 2019, o pterossaurólogo e paleobiólogo Felipe Pinheiro, da Universidade Federal do Pampa (Campus São Gabriel), e colaboradores, identificaram a composição química de pigmentos orgânicos originais de melanina em tecidos moles da crista do pterossauro Tupandactylus imperator por meio de técnicas, por exemplo, de microscopia eletrônica de varredura e de cromatografia líquida de alta performance (PINHEIR0 et al., 2019). Inclusive, revelando que o fóssil de pterossauro contém eumelanina original no interior dos melanossomas preservados os quais são indistinguíveis das organelas contendo melanina de vertebrados modernos. Essa pesquisa representa uma nova proposta de inferência de cores baseada na característica química dos pigmentos em tecidos moles. Além desses, outros estudos também já descobriram tecidos moles em fósseis de pterossauros brasileiros (CAMPOS et al., 1984; CAMPOS; KISCHLAT, 2020).

Em 2020, pesquisadores brasileiros e estrangeiros fizeram um estudo de tafonomia experimental usando esteiras microbianas a fim de entender o decaimento e a preservação excepcional por meio da mineralização de diferentes tecidos moles de larvas de insetos atuais, seccionando-as histologicamente e analisando-as sob microscopia eletrônica de varredura e técnicas de paleometria, e finalmente comparando-as com as de tecidos moles mineralizados de fósseis grilóides cretácicos oriundos da Formação Crato (INIEST0 et al., 2020).

Desde 2020, eu e alguns colaboradores também temos contribuído para aumento do conhecimento científico neste campo de estudo a partir de uma linha de pesquisa teórica pioneira que se concentra em aspectos históricos e educacionais e na investigação da Frequência de 0corrência de achados de biomateriais não mineralizados em fósseis de diferentes grupos taxonômicos (ALVES, 2020; ALVES; MACHAD0, 2020; GOMES et al., 2020a; 2020b; ALVES, 2021). 0s resultados de nossos estudos estão agora disponíveis para servir de base para elaboração de novas propostas de pesquisa que utilizem os mais diversos métodos e abordagens, assim como para estimular ainda mais o interesse pelo campo da Paleontologia Molecular no Brasil. 
Em síntese, o campo da Paleontologia Molecular está em constante avanço mundial e é uma área onde a ciência brasileira também poderia atuar mais pelo importante material fossilífero que dispõe. Por outro lado, espero que as descobertas que já foram feitas em solo nacional, embora embrionárias, abram caminho para que novos grupos de pesquisa no país invistam em técnicas e laboratórios especializados para a investigação de diversos tipos de biomoléculas originais que provavelmente se encontram em fósseis brasileiros.

\section{REFERÊNCIAS BIBLIOGRÁFICAS}

ALVES, E.F. 15 anos da Paleontologia molecular: breve histórico dos achados de tecidos moles não mineralizados em dinossauros não avianos. Khronos, Revista de História da Ciência, v. 9, p. 241-244, 2020.

ALVES, E.F.; MA-CHAD0, M.F. Perspectivas atuais sobre tecidos moles não mineralizados em fósseis de dinossauros não avianos. TerræDidatica, v. 16, p.1-14, e020028, 2020.

ALVES, E. F. Uma entrevista com Dawid Surmik: pesquisa e ensino da Paleontologia Molecular. Pesquisa e Ensino em Ciências Exatas e da Natureza, v. 5, n. el651, p. 1-4, 2021.

BECKER, B. K, OSÉS, G. L.; MASSINI, R. R. R. C.; CURADO, J. F.; DELGADO, A. O.; GALANTE, D.; RODRIGUES, F.; RIZZUTTO, M. A.; PETRI, S.; LEME, J. M.; PACHECO, M. L. A. F.0 estabelecimento da paleometria no Brasil: perspectivas e desafios no estudo de invertebrados fósseis. In: II Simpósio Brasileiro de Paleoinvertebrados, Ponta Grossa, 2014. Paleontologia em destaque: Boletim informativo da Sociedade Brasileira de Paleontologia, edição especial, p. 27-34, 2014.

CAMPOS, D. A.; LIGABUE, D.; TAQUET, P. Wing membrane and wing supporting fibres of a flying reptile from the Lower Cretaceous of the Chapada do Araripe (Aptian; Ceará State, Brazil). In: Reif, E., Westphal, F. (Eds.). Proc. 3rd Symp. Mesozoic Terrestrial Ecosystems, Short Papers, Tübingen, Germany, p. 37-39, 1984.

FREY, E.; TISCHLINGER, H. Weichteilanatomie der Flugsaurierfüßeund Ban der Scheitelkämme: Neue PterosaurierfundeausdenSolnhofenerSchichten (Bayern) und der Crato-Formation (Brasilien). Archaeopteryx, v. 18, p. 1-16, 2020.

FREY, E.; TISCHLINGER, H.; BUCHY, M. C.; MARTILL, D. M. New specimens of Pterosauria (Reptilia) with soft parts with implications for pterosaurian anatomy and locomotion. Geological Society, London, Special Publications, v. 217, n. 1, p. 233-266, 2003.

GOMES, W.A.; MACHADO, M.F.; BÉLO, P.; ALVES,E.F. Paleontologia molecular do Cenozoico: reivindicações de tecidos moles não mineralizados em mamíferos encontrados em depósitos sedimentares pouco favoráveis à preservação. In: Paleo RJ/ES Virtual, Vitória-ES, 2020a.

GOMES, W.A.; MACHADO, M.F.; BÉLO, P.; ALVES, E.F. Biomoléculas em fósseis de mamíferos cenozoicos: reivindicações de tecidos moles não mineralizados em fósseis recuperados de diferentes contextos tafonômicos. In: Paleo RJ/ES Virtual, Vitória-ES, 2020b.

INIESTO, M.;GUTIÉRREZ-SILVA, P.; DIAS, J. J.; CARVALHO, I. S.; BUSCALIONI, A. D.; LÓPEZ-ARCHILLA, A. I. Soft tissue histology of insect larvae decayed in laboratory experiments using microbial mats: Taphonomic comparison with cretaceous fóssil insects from the exceptionally preserved biota of Araripe, Brazil. Palaeogeography, Palaeoclimatology, Palaeoecology, n. 110156, 2020.

KELLNER, A. W. A. Short Note on a new dinosaur (Theropoda, Coelurosauria) fromthe Santana Formation (Romualdo Member, Albian), northeasternBrazil. Boletim do Museu Nacional (Serie Geologia), v. 49, p. 1-8, 1999.

KELLNER, A. W. A.; WANG, X.; TISCHLINGER, H.; CAMPOS, D. A.; HONE, D. W. E.; MENG, X. The soft tissue of Jeholopterus (Pterosauria, Anurognathidae, Batrachognathinae) and the structure of the pterosaur wing membrane. Proceedingsofthe Royal Society B, v. 277, n. 1679, p. 321-329, 2009. 
KELLNER, A. W. A.; SOARES, M. B. EDITORIAL NOTE: Collection of Paleontology Papers in honor of the Centenary of the Brazilian Academy of Sciences. Anais da Academia Brasileira de Ciências, v. 91, suppl. 2, p. e20191434, 2019.

LIMA, R. J. C.:SARAIVA, A. A. F.; LANFrEDI, S.; NOBRE, M. A. L.; FREIRE, P. T. C.; SASAKI, J. M. Caracterização espectroscópica de peixe do período cretáceo (Bacia do Araripe). Química Nova, v. 30, n. 1, p. 22-24, 2007.

MARTILL, D. M. The Medusa Effect: InstantaneousFossilization. Geology Today, v. 5, p. 201-205, 1989.

MARTILL, D. M.; UNWIN, D. M. Exceptionally well preserved pterosaur wing membrane from the Cretaceous of Brazil. Nature, v. 340, n. 6229, p. 138-140, 1989.

OSÉS,G. L.;PETRI, S.; BECKER-KERBER, B.; ROMER0, G. R.; RIZZUTTO, M. A.; RODRIGUES, F.; GALANTE, D.; DA SILVA, T. F.; CURADO, J. F.; RANGEL, E. C.; RIBEIR0, R. P.; PACHECO, M. L. A. F. Deciphering the preservation of fóssil insects: a case study from the Crato Member, Early Cretaceous of Brazil. PeerJ, v. 4, p. e2756, 2016.

OSÉS, G.L.; PETRI, S.; VOLTANI, C.G.; PRADO, G. M. E. M.; GALANTE, D.; RIZZUTTO, M. A.; RUDNITZKI, I. D.; DA SILVA, E. P.; RODRIGUES, F.; RANGEL, E. C.; SUCERQUIA, P. A.; PACHECO, M. L. A. F. Deciphering pyritization-kerogenization gradient for fish soft-tissue preservation. Scientific Reports,v. 7, n.1468, 2017.

PEREIRA, R.;CARVALHO, I. S.; AZEVED0, D. A. Afinidades paleobotânicas de âmbares cretácicos das bacias do Amazonas, Araripe e Recôncavo. Geociências, v. 25, n. 2, p. 217-224, 2006.

PEREIRA, R.;CARVALHO, I. S.; SIMONEIT, B. R. T.; AZEVEDO, D. A. Molecular composition and chemosystematic aspects of Cretaceous amber from the Amazonas, Araripe and Recôncavo basins, Brazil. Organic Geochemistry, v. 40, n. 8, p. $863-875,2009$ a.

PEREIRA, R.;CARVALHO, I. S.; FERNANDES, A. C. S.; AZEVED0, D. A. Composição molecular e origem paleobotânica de âmbares da bacia do Araripe, Formação Santana. Química Nova, v. 32, n. 6, p. 1528-1533, 2009 b.

PEREIRA, R.;CARVAlHO, I. S.; FERNANDES, A. C. S.; AZEVEDO, D. A. Chemotaxonomical aspects of lower Cretaceous amber from Recôncavo Basin, Brazil. Journal of the Brazilian Chemical Society, v. 22, n. 8, p. 1511-1518, 2011 .

PEREIRA, R.;CARVAlH0, I. S.; FERNANDES, A. C. S.; AZEVED0, D. A. Composição molecular, aspectos quimiotaxonômicos e origem botânica de âmbares brasileiros. Revista Virtual de Química, v. 3, p. 145-158, 2011 b.

PEREIRA, R.;de LIMA, F. J.; SIMBRAS, F. M.; BITTAR, S. M. B.; KELLNER, A. W. A.; SARAIVA, A. A. F.; BANTIM, R. A. M.; SAYÃO, J. M.; OLIVEIRA, G. R. Biomarker signatures of Cretaceous Gondwana amberfrom Ipubi Formation (Araripe Basin, Brazil) and their palaeobotanical significance. Journalof South American Earth Sciences, v. 98, n. 102413, 2020.

PINHEIR0, F. L.; PRAD0, G.; ITO, S.; SIMON, J. D.; WAKAMATSU, K.; ANELLI, L. E.; ANDRADE, J. A. F.; GLASS, K. Chemical characterization of pterosaur melanin challenges color inferences in extinctanimals. Scientific Reports, v. 9, n. $15947,2019$.

PRAD0,G. M. E. M.;ANELLI, L. E.; PACHECO, M. L. A. F.; PETRI, S.; ROMER0, G. R. Systematic and taphonomic insights of fossilized feathers: A new occurrence from the Oligocene of Taubaté Basin (SE, Brazil). Journalof South American Earth Sciences, v. 72, p. 169-177, 2016a.

PRAD0,G. M. E. M.;ANELLI, L. E.; PETRI, S.; ROMER0, G. R. New occurrences of fossilized feathers: systematics and taphonomy of the Santana Formation of the Araripe Basin (Cretaceous), NE, Brazil. PeerJ, v. 4, n. 3, p. el916, $2016 \mathrm{~b}$.

SAYÃ0, J. M.; BANTIM,R. A. M. A paleontologia no século XXI: novas técnicas e interpretações. Ciência e Cultura, v. 67, n. 4, p. 45-49, 2015.

SCHWEITZER, M.H. Reviews and Previews: The Future of Molecular Biology. Palaeontologia Electronica,v.5, n. 2, editorial 2, p. 1-11, 2003.

SCHWEITZER, M.H. Molecular paleontology: some current advances and problems. Annales de Paléontologie,v. 90, n. 2, p. 81-102, 2004. 
Investigações Brasileiras em Busca de Tecidos Moles Preservados em Fósseis

SMYTH,R. S. H.; MARTILL, D. M.; FREY, E.; RIVERA-SYLVA, H. E.; LENZ, N. A maned theropod dinosaur from Gondwana with elaborate integumentary structures. Cretaceous Research, n. 104686, in Press, 2020.

VINTHER, J.; BRIGGS, D.E.; PRUM, R.0.; SARANATHAN, V. The colour of fóssil feathers. Biology letters, v. 4, n. 5, p. 522 525,2008 